\title{
COMPARISON OF MICROWAVE BACKSCATTER ANISOTROPY PARAMETERISATIONS OVER THE ANTARCTIC ICE SHEET
}

\author{
Alexander D. Fraser ${ }^{a}$, Neal W. Young ${ }^{a, b}$ and Neil Adams ${ }^{c}$ \\ ${ }^{a}$ Antarctic Climate \& Ecosystems Cooperative Research Centre \\ University of Tasmania \\ Private Bag 80 \\ Hobart, Tasmania, Australia, 7001 \\ adfraser@utas.edu.au \\ ${ }^{b}$ Australian Antarctic Division \\ Channel Highway \\ Kingston, Tasmania, Australia, 7050 \\ ${ }^{c}$ Australian Bureau of Meteorology \\ GPO Box 727 \\ Hobart, Tasmania, Australia, 7001
}

Commission VIII/10

KEY WORDS: Snow, Ice, Glaciology, Research, Active, Microwave, Satellite

\begin{abstract}
:
The Antarctic Ice Sheet exhibits a strong anisotropy in microwave backscatter, both as a function of azimuth angle and incidence angle. This anisotropy arises as a result of i) the alignment of roughness elements and other wind-related surface and sub-surface features, as well as ii) internal layers and snow grain size gradient within the snowpack. As a result of its antenna configuration, the European Organisation for the Exploitation of Meteorological Satellites (EUMETSAT) Advanced SCATterometer (ASCAT) satellite instrument is able to observe much of the continent with a large azimuth and incidence angle diversity. A lack of azimuth and incidence diversity has restricted previous backscatter parameterisations to relatively simple bi-sinusoidal (azimuth angle) and linear (incidence angle) parameterisations. Using ASCAT, we show that a better fit can be obtained using a cubic incidence angle function and a Fourier series of up to four terms for parameterisation of the azimuth angle anisotropy. Scatterometer instruments have previously been used in Greenland to retrieve accumulation rate by observing the change in backscatter as a function of incidence angle. Here we present preliminary results of an empirical study linking the isotropic component and incidence angle dependence to snow accumulation rate in Antarctica, using snow stake measurements as ground truthing.
\end{abstract}

\section{INTRODUCTION}

Surface mass balance (SMB) is the net input term for ice mass balance calculations and is thus a critical parameter for accurate estimation of the Antarctic Ice Sheet (AIS) contribution to sea level rise (Allison et al., 2009). Despite this, reliable in-situ measurements of SMB are sparse throughout the AIS, particularly in the interior of the continent where few staffed stations exist. The mass input to the AIS can be determined from knowledge of the spatial distribution of SMB (the spatial integral of which gives the total mass input), and the temporal variations of this. Spatial extensions of sparse in-situ data can be provided by either modeling or large-scale observation. Recent advances in atmospheric modeling capability (e.g., Lenaerts et al. (2012) included the effects of snow redistribution due to blowing snow) have given rise to highresolution, large-scale maps of SMB throughout the AIS. Satellite remote sensing of SMB provides an indepentent large-scale spatial extension of in-situ point and line measurements such as snow stakes (e.g., Higham et al. (1997)) and ground penetrating radarderived isochronous horizons (e.g., Müller et al. (2010)). Passive microwave thermal emission signals are sensitive to SMB, and several studies have explored these links in detail, e.g., Winebrenner et al. (2001); Arthern et al. (2006). Empirically-derived relationships between SMB and scatterometer measurements have been studied in Greenland, but no equivalent study has yet been conducted in Antarctica.
Scatterometers are typically spaceborne, active instruments originally designed to obtain microwave backscatter measurements from small scale roughness on the surface of the ocean for multiple azimuth angles. From this information, surface wind strength and direction can be inferred. For approximately two decades, spaceborne scatterometer instruments have also been applied to the great ice sheets in Greenland (e.g., Long et al. (1992)) and Antarctica (e.g., Remy et al. (1992)), in order to retrieve surface and near-surface snow parameters. Large parts of the surface of both the Greenland Ice Sheet (GrIS) and Antarctic Ice Sheet (AIS) are characterised by sastrugi (wind-aligned snow structural features of magnitude depending on wind speed at the time of formation, rarely greater than $50 \mathrm{~cm}$ in height (Kobayashi, 1980)). Microwave backscatter is enhanced by several dB when looking across these roughness features (Furukawa and Young, 1997). For non-nadir microwave observations of the great ice sheets, a large azimuthal diversity of observation is essential, in order to accurately characterise this strong azimuthal anisotropy.

A more in-depth review of past ice sheet applications of scatterometer data to be provided in a forthcoming publication (Fraser et al., in prep.) is summarised here. Much of the early scatterometer work on ice sheets was focused around retrieval of sastrugi parameters (magnitude and direction) using the bi-sinusoidal azimuthal modulation, e.g., Ledroit et al. (1993); Young et al. (1996); Furukawa and Young (1997); Hyland and Young (1998); Long 
and Drinkwater (2000). Other cryospheric applications of scatterometer data include iceberg tracking (Young and Hyland, 1997), surface melt detection and facies classification (e.g., Oza et al. (2011); Long and Drinkwater (1994); Drinkwater and Long (1998)) Since many scatterometers also observe the surface at a range of incidence angles, the dependence of backscatter on incidence angle can be exploited to retrieve physical parameters of the snow/ firn, e.g., snow grain size (Ulaby et al., 1996) and SMB (Drinkwater et al., 2001). This latter study found an empirical relationship between SMB and the slope of the backscatter dependence on incidence angle. With the aid of a multilayer scattering model, this dependence was mainly attributed to changes in grain size profile as a function of SMB, and the presence of dielectric discontinuities in the form of horizontal layers generated either by annually-recurring patterns of snow accumulation, or changes in near-surface meteorological conditions (Drinkwater et al., 2001). It is worth emphasising that this is not a direct retrieval of SMB or accumulation rate, but a complex combination of factors which are related to SMB, i.e., grain size (a function of temperature and time since deposition), the presence/absence of dielectric layers (which can be annual, and hence related to SMB, but also can be sub-annual in the case of wind glaze or episodic snowfall events). Since there is often a dominant azimuthal modulation of surface backscatter from the Antarctic snow cover, particularly in katabatic wind regimes where snow micro-roughness can become strongly mono-directional, this must be accurately characterised and removed before sub-surface parameters (e.g., SMB) can be accurately retrieved.

The EUMETSAT Advanced SCATterometer (ASCAT) instrument was launched in 2007 aboard the MetOp-A satellite. The twosided antenna configuration of ASCAT gathers data from two 500 $\mathrm{km}$ wide swaths separated by a nadir band $700 \mathrm{~km}$ wide to provide a combined diversity in incidence and azimuthal observation directions. ASCAT is a C-band scatterometer, with a 29-day repeat orbit. Antenna beams are oriented $45^{\circ}$ fore, abeam, and $45^{\circ}$ aft of the satellite track. Incidence angle observations range between $\sim 25^{\circ}$ and $65^{\circ}$ (Figa-Saldaña et al., 2002).

The excellent azimuth and incidence angle diversity offered by ASCAT raises the possibility of using complex parameterisations to represent the backscatter anisotropy. With a few exceptions, i.e., Long and Drinkwater (2000); Long et al. (2003); Ashcraft and Long (2006); Lambert and Long (2008), parameterisations have been limited to relatively simple second-order Fourier series for azimuth anisotropy parameterisation, and to a linear relationship between backscatter and incidence angle. Here, we investigate the empirical relationships between snow stake-derived measurements of SMB on the AIS, using a Fourier series of order 1,2 and 4 for azimuth $(\phi)$ anisotropy parameterisation, and linear and cubic polynomials for incidence $(\theta)$ anisotropy parameterisation. We remove the third order Fourier term in the parameterisation due to its relatively small value throughout most of the AIS (Fraser et al., in prep.). The two parameterisations used in this work are:

Linear incidence angle parameterisation:

$$
\begin{aligned}
\sigma_{0} & =A+B\left(\theta-40^{\circ}\right)+\cos \left(1\left(\phi-\phi_{1}\right)\right) \\
& +\cos \left(2\left(\phi-\phi_{2}\right)\right)+\cos \left(4\left(\phi-\phi_{4}\right)\right)
\end{aligned}
$$

Cubic incidence angle parameterisation:

$$
\begin{aligned}
\sigma_{0} & =A+B_{3}\left(\theta-40^{\circ}\right)^{3}+B_{2}\left(\theta-40^{\circ}\right)^{2} \\
& +B_{1}\left(\theta-40^{\circ}\right)+\cos \left(1\left(\phi-\phi_{1}\right)\right) \\
& +\cos \left(2\left(\phi-\phi_{2}\right)\right)+\cos \left(4\left(\phi-\phi_{4}\right)\right)
\end{aligned}
$$

Where, $A$ represents the isotropic component of backscatter. In the linear parameterisation, $B$ the linear coefficient relating backscatter to incidence angle. This is generalised to a cubic polynomial in the cubic parameterisation, with the linear coefficient designated $B_{1}$. The incidence angle is normalised to a mid-range value of $40^{\circ}$. A more complete comparison of parameterisations will be presented in a forthcoming publication (Fraser et al., in prep.).

\section{METHODS}

"Gridded-swath" ASCAT Level 1B (data code "ASCA_SZR_1B") data were obtained from the EUMETSAT data centre (http://www. eumetsat.int), and gridded to a polar stereographic projection, with a ground resolution of approximately $12.5 \mathrm{~km}$. The study period was chosen to a) cover at least one repeat cycle of the MetOp-A satellite (29 days), giving the maximum possible azimuth and incidence diversity, and b) coincide with stable, well below freezing conditions throughout the AIS. Thus, a thirty day period from Day Of Year (DOY) 211, 2010 to DOY 240, 2010 was chosen. Data used in this study were backscatter, azimuth angle, incidence angle, and $K_{p}$ (the normalised RMS error in backscatter).

For each pixel in the output grid, least-squares fitting was performed to both the cubic and linear parameterisation, using the freely-available MPFIT program (Markwardt, 2009), written for ITT's Interactive Data Language (IDL) software suite. This returns values for each of the parameters in the model. Fits were weighted by the $K_{p}$ value. Here, the $A$ and $B$ (linear) $/ B_{1}$ (cubic) parameters are empirically compared to measurements of SMB from snow stake traverses throughout Wilkes Land $\left(\sim 95-130^{\circ}\right.$ E) and around the Lambert Glacier Basin (LGB, $\left.\sim 55^{\circ}-65^{\circ} \mathrm{E}\right)$.

The LGB traverses (Higham and Craven, 1997; Higham et al., 1997) were conducted in the early 1990s. For the traverse section presented here ("LGB00 - 35"), the interval between deployment and final SMB measurement is approximately 3 years (NovDec 1990 to Nov-Dec 1993), satisfying the Magand et al. (2007) requirement for high-quality snow stake measurements of SMB to be multi-year. The Wilkes Land traverses were conducted in the early 1980s, and were taken over intervals of either 3 years ("West" and "East") or 5 years ("South"). In both the Wilkes and LGB traverses, snow stakes were placed approximately every $2 \mathrm{~km}$. The Wilkes Land East and West, as well as the LGB traverses all approximately follow the 2,000 m contour, whereas the Wilkes Land South traverse tracks approximately southward to $\sim 3,000$ m elevation. All traverse routes are marked in Figure 1. For an initial appraisal, Wilkes Land traverse snow stake data were averaged together in each gridded satellite pixel where snow stake observations were made (maximum of seven $2 \mathrm{~km}$ interval snow stake measurements in a $\sim 12.5 \mathrm{~km}$ pixel). For the LGB traverse data, following the method of Higham and Craven (1997), SMB measurements were smoothed by an unweighted filter of 30 $\mathrm{km}$ width, to remove high frequency temporal and spatial noise. A more consistent averaging scheme cognizant of the scatterometer beam pattern will be adopted in future work.

\section{RESULTS AND DISCUSSION}

After Drinkwater et al. (2001) working in the Greenland dry snow zone, we performed a least-squares fitting of the form $S M B=$ $e^{a-b x}$, where $x$ is the " $A$ " parameter (isotropic component of backscatter), " $B$ " parameter (dependence of backscatter on incidence angle for the linear incidence angle parameterisation), or " $B_{1}$ " (linear component of backscatter dependence on incidence 


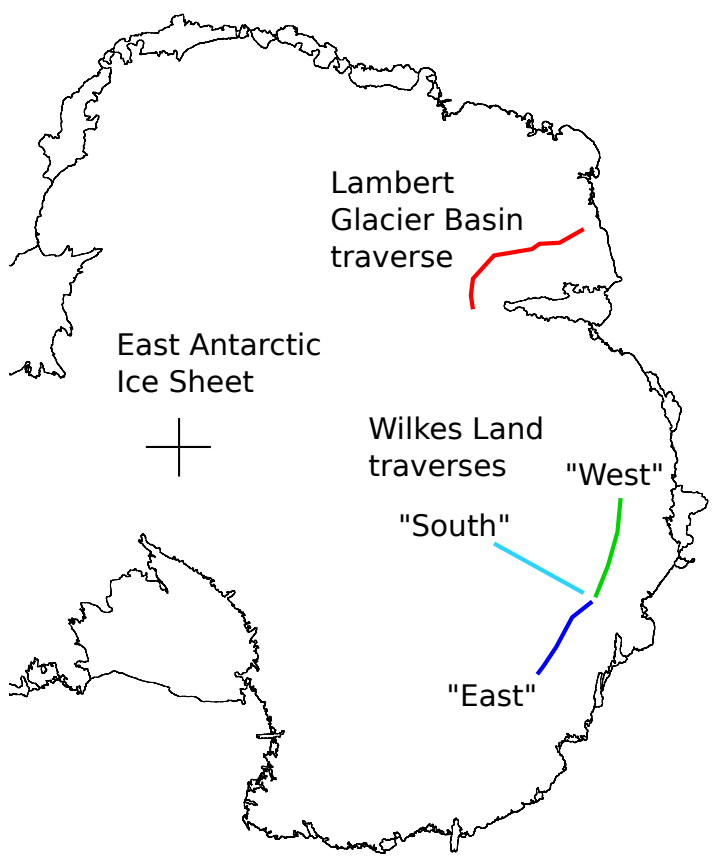

Figure 1: Australian traverse routes for measuring SMB using snow stakes.

angle for the cubic incidence angle parameterisation). These three plots are shown in Figure 2.

All three sub-figures show a relatively robust empirical relationship between SMB and $A, B$ or $B_{1}$. Table 1 shows that the order of increasing RMS residual is South, LGB, East, West, regardless of the parameter being fitted against SMB. Analysis of individual, unfiltered snow stake measurements suggests that much of the West traverse route crosses a region where accumulation rate is low and surface wind glaze conditions are prevalent. Similar conditions were also encountered throughout the LGB traverse, to a lesser extent (Higham and Craven, 1997), though the lower residual can likely be attributed to lower values of SMB encountered here.

Drinkwater et al. (2001) discovered SMB had a stronger relationship with the $B$ parameter than with the $A$ parameter, i.e., the incidence angle anisotropy is more sensitive to changes in SMB than the isotropic component. In the present study, we find a lower RMS residual in the empirical fit between SMB and $A(0.20 \mathrm{~m}$ accumulation/annum), than with SMB and $B$ $(0.24 \mathrm{~m} / \mathrm{annum})$ or $B_{1}(0.27 \mathrm{~m} / \mathrm{annum})$. We note that in the Greenland dry snow zone, there are annual layers that exhibit a strong dielectric contrast, likely a result of autumnal hoarfrost formation (Hawley et al., 2006). Complex interactions between precipitation-bearing synoptic systems and local orography are important along the East Antarctic coast (e.g., a large snowfall gradient exists between the eastern and western sides of Law Dome, centred at $\sim 112.5^{\circ} \mathrm{E}, 66.5^{\circ} \mathrm{S}$ ), and may explain the wider range of observed A and B parameters in the Wilkes Land West traverse than the East. Furthermore, in regions of persistent wind glaze and low accumulation (e.g., parts of the Wilkes Land West traverse route), annual dielectric layers may not exist in the snow/ upper firn. Thus, the relationship between incidence angle anisotropy and SMB likely varies regionally, particularly along the East Antarctic coast. In such regions, it comes as no surprise that the $A$ parameter gives a better indication of SMB than the $B$ parameters, since $A$ is a strong function of near-surface snow grain size (Ulaby et al., 1996), and in the absence of accumulation, grain size metamorphism/growth continues to occur at the
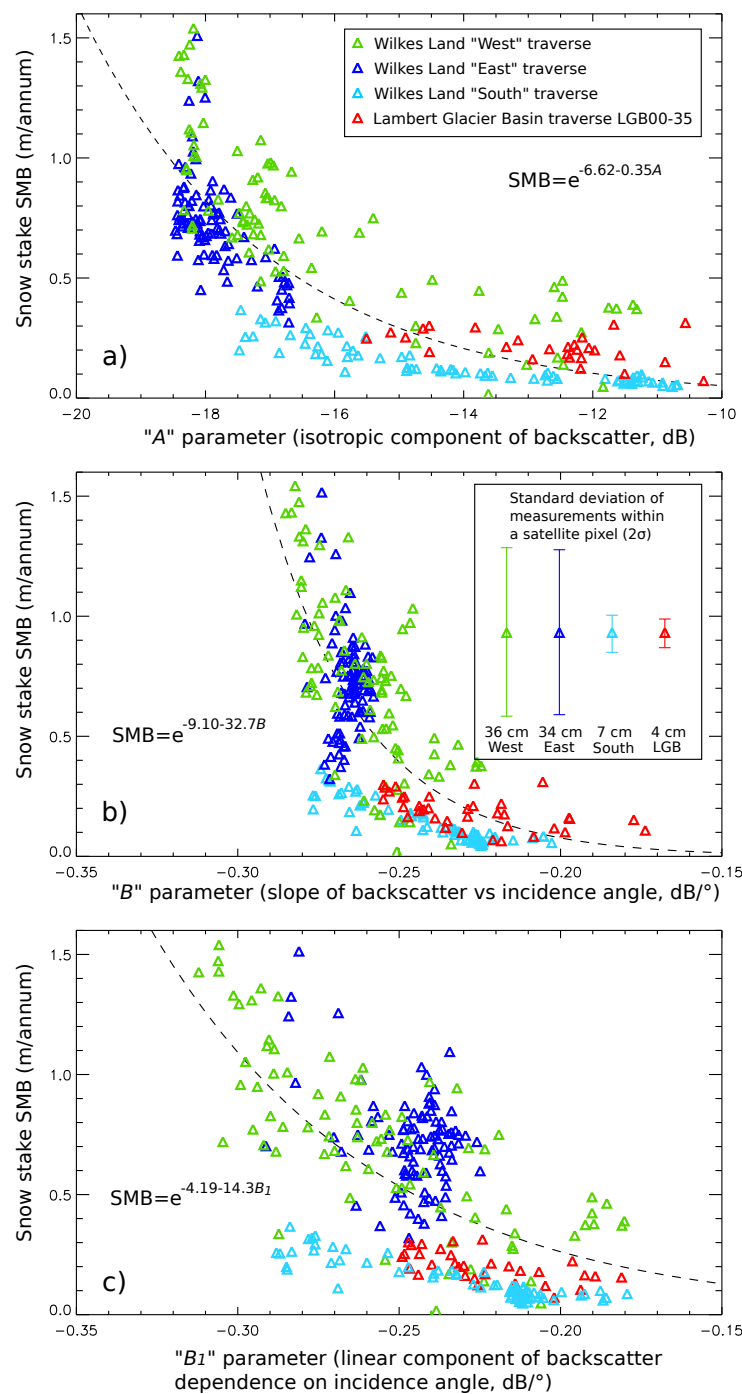

Figure 2: a) SMB vs " $A$ " parameter for the linear parameterisation (cubic is very similar, so not shown here). b) SMB vs " $B$ " parameter for the linear parameterisation. c) SMB vs " $B_{1}$ parameter for the cubic parameterisation. The least-squares fit using a model of the form $S M B=e^{a-b x}$ is shown with the dashed line, where $\mathrm{x}$ is the " $A$ " parameter for panel a), " $B$ " for $\mathrm{b}$ ), and " $B_{1}$ ", for c), after Drinkwater et al. (2001) in Greenland.

surface, giving higher backscatter at sites of lower accumulation.

The addition of the 4th order Fourier term to the linear azimuth angle parameterisation results in a statistically-significant reduction in curve-fitting residual from 0.66 to $0.46 \mathrm{~dB}$, averaged over the whole AIS, using 30 days' ASCAT observations. Addition of the cubic incidence angle parameterisation results in a further drop in residual fit (from 0.46 to $0.43 \mathrm{~dB}$ ), again statisticallysignificant, as shown by an F-test. Comparison between the linear and cubic incidence angle parameterisations (Figures $2 \mathrm{~b}$ and c) reveals that while the residual is slightly lower for the linear incidence angle parameterisation case (except for the South traverse), there is also less sensitivity to differences in SMB in the linear case. This is encouraging from a SMB retrieval perspective. This parameterisation, and others using a cubic incidence angle parameterisation, will be compared in a forthcoming paper (Fraser et al., in prep.). 
Table 1: RMS residual of individual least-squares fits for each traverse route.

\begin{tabular}{|l||l|r|r|}
\hline Parameter fit & Traverse & n & Residual RMS \\
\hline \hline A (linear and cubic) & South & 70 & 0.034 \\
\hline \hline & West & 82 & 0.19 \\
\hline & East & 93 & 0.16 \\
\hline & LGB & 36 & 0.051 \\
\hline \hline B (linear) & South & 70 & 0.034 \\
\hline & West & 82 & 0.24 \\
\hline & East & 93 & 0.2 \\
\hline & LGB & 36 & 0.056 \\
\hline \hline B1 (cubic) & South & 70 & 0.039 \\
\hline & West & 82 & 0.22 \\
\hline & East & 93 & 0.19 \\
\hline & LGB & 36 & 0.052 \\
\hline
\end{tabular}

\section{CONCLUSIONS AND FUTURE WORK}

This work forms an important first step in establishing an empirical link between SMB and remotely-sensed scatterometer-derived parameters in Antarctica. While significant spread in SMB retrieval is observed from challenging surface conditions, i.e, from the Wilkes Land West and East traverse routes, it is encouraging to see similarly accurate retrievals of SMB values from geographically distant locations and from different altitudes/snowfall regimes.

We aim to extend this work by empirically linking SMB to scatterometer-derived parameter retrievals using more extensive ground validation, i.e., as in Lenaerts et al. (2012). Furthermore, additional ground truthing will be provided by the Norway-US traverse ground penetrating radar data, which gives long-term SMB average from the deposition of the Tambora volcanic eruption emissions ( 1816) to 2007, high on the Antarctic plateau (Müller et al., 2010).

It is clear that more accurate SMB retrievals will require the use of complementary remote sensing data, either in the form of different frequency scatterometer data (altering the penetration depth, volume backscatter from snow grains, and surface backscatter from sastrugi/microrelief), fully polarimetric scatterometer data (allowing better characterisation of surface scattering), visible/ near IR surface grain size data, or inclusion of passive microwave emission data. The last option, a fusion of passive and active microwave observations, is being addressed in current work.

\section{ACKNOWLEDGEMENTS}

This work was supported by the Australian Government's Cooperative Research Centres Program through the Antarctic Climate \& Ecosystems Cooperative Research Centre (ACE CRC). ASCAT Level 1B data were provided by the EUMETSAT Data Centre version 3 (http://www.eumetsat.int). The authors wish to thank J. Jacka and B. Legrésy for discussions about snow/firn structure/metamorphism and radar backscatter from snow/firn respectively. The authors also wish to thank M. "Duk" Craven for providing and assisting with the LGB traverse data, and G. Hyland for helpful comments on the manuscript.

On the 23rd March 2012 at the age of 51 Neil Adams passed away suddenly. He leaves behind him a tremendous legacy to the Antarctic and meteorological community. Neil has been nationally and internationally recognised for his dedication to, and role in, advancing the science and wide-spread application of meteorology particularly in the fields of data presentation, high-latitude meteorology and service provision. Neil contributed to several national and international polar-related committees/forums. His many authored and co-authored peer-reviewed papers are further testament to his inherent professionalism and expertise. Neil is sadly missed by his many colleagues in the Antarctic community.

Biography provided by P. Reid, Australian Bureau of Meteorology (Centre for Australian Weather and Climate Research).

\section{References}

Allison, I., Alley, R. B., Fricker, H. A., Thomas, R. H. and Warner, R. C., 2009. Ice sheet mass balance and sea level. Antarctic Science 21(5), pp. 413-426.

Arthern, R. J., Winebrenner, D. P. and Vaughan, D. G., 2006. Antarctic snow accumulation mapped using polarization of 4.3-cm wavelength microwave emission. Journal of Geophysical Research (Atmospheres) 111, pp. D06107.

Ashcraft, I. S. and Long, D. G., 2006. Relating microwave backscatter azimuth modulation to surface properties of the Greenland ice sheet. Journal of Glaciology 52, pp. 257-266.

Drinkwater, M. and Long, D., 1998. Seasat, ers-1/2 and nscat scatterometer observed changes on the large ice sheets. In: Geoscience and Remote Sensing Symposium Proceedings, 1998. IGARSS '98. 1998 IEEE International, Vol. 4, pp. 2252 -2254 vol. 4 .

Drinkwater, M. R., Long, D. G. and Bingham, A. W., 2001. Greenland snow accumulation estimates from satellite radar scatterometer data. Journal of Geophysical Research 106, pp. 33935-33950.

Figa-Saldaña, J., Wilson, J. J., Attema, E., Gelsthorpe, R., Drinkwater, M. R. and Stoffelen, A., 2002. The advanced scatterometer (ASCAT) on the meteorological operational (MetOp) platform: A follow on for European wind scatterometers. Canadian Journal of Remote Sensing 28(3), pp. 404-412.

Fraser, A. D., Young, N. W. and Adams, N., in prep. A comparison of microwave backscatter anisotropy parameterisations of the antarctic ice sheet using ascat. To be submitted to IEEE Transactions on Geoscience and Remote Sensing.

Furukawa, T. and Young, N. W., 1997. Comparison of microwave backscatter measurements with observed roughness of the snow surface in East Queen Maud Land, Antarctica. In: Proceedings of the 3rd ERS Symposium, Florence.

Hawley, R. L., Morris, E. M., Cullen, R., Nixdorf, U., Shepherd, A. P. and Wingham, D. J., 2006. ASIRAS airborne radar resolves internal annual layers in the dry-snow zone of Greenland. Geophysical Research Letters 330, pp. 4502.

Higham, M. and Craven, M., 1997. Surface Mass Balance and Snow Surface Properties from the Lambert Glacier Basin Traverses 1990-94. Research report 9, Antarctic CRC, Private Bag 80, Hobart, Tasmania, 7001, Australia.

Higham, M., Craven, M., Ruddell, A. and Allison, I., 1997. Snow-accumulation distribution in the interior of the Lambert Glacier basin, Antarctica. Annals of Glaciology 25, pp. 412417.

Hyland, G. and Young, N., 1998. Wind-induced directional anisotropy of microwave backscatter and its impact on imaging of the Antarctic continental snow cover. In: IEEE International Geoscience and Remote Sensing Symposium (IGARSS) Proceedings. 
Kobayashi, S., 1980. Studies on Interaction Between Wind and Dry Snow Surface.

Lambert, B. and Long, D. G., 2008. Monitoring changes in the Antarctic Ice Sheet form 1978 to 2007. In: Proceedings of the IEEE International Geoscience and Remote Sensing Symposium (IGARSS).

Ledroit, M., Rémy, F. and Minster, J.-F., 1993. Observations of the Antarctic ice sheet with the Seasat scatterometer: relation to katabatic-wind intensity and direction. Journal of Glaciology 39, pp. 385-396.

Lenaerts, J. T. M., van den Broeke, M. R., van de Berg, W. J., van Meijgaard, E. and Kuipers Munneke, P., 2012. A new, high-resolution surface mass balance map of Antarctica (19792010) based on regional atmospheric climate modeling. Geophysical Research Letters 39, pp. 4501.

Long, D. G. and Drinkwater, M. R., 1994. Greenland ice-sheet surface properties observed by the Seasat-A scatterometer at enhanced resolution. Journal of Glaciology 40, pp. 213-230.

Long, D. G. and Drinkwater, M. R., 2000. Azimuth variation in microwave scatterometer and radiometer data over Antarctica. IEEE Transactions on Geoscience and Remote Sensing 38, pp. 1857-1870.

Long, D. G., Ashcraft, I. S. and Luke, J. B., 2003. Radar scatterometer observations of sastrugi on the great ice sheets. In: W. L. Barnes (ed.), Society of Photo-Optical Instrumentation Engineers (SPIE) Conference Series, Society of PhotoOptical Instrumentation Engineers (SPIE) Conference Series, Vol. 5151, pp. 85-93.

Long, D. G., Hardin, P. J. and Shaw, R. A., 1992. Greenland observed at a high resolution by the Seasat Scatterometer. In: IEEE International Geoscience and Remote Sensing Symposium Proceedings, Vol. 5, pp. 327-329.

Magand, O., Genthon, C., Fily, M., Krinner, G., Picard, G., Frezzotti, M. and Ekaykin, A. A., 2007. An up-to-date qualitycontrolled surface mass balance data set for the $90^{\circ}-180^{\circ} \mathrm{E}$ Antarctica sector and 1950-2005 period. Journal of Geophysical Research (Atmospheres) 112, pp. 12106.

Markwardt, C. B., 2009. Non-linear Least-squares Fitting in IDL with MPFIT. In: D. A. Bohlender, D. Durand, \& P. Dowler (ed.), Astronomical Data Analysis Software and Systems XVIII, Astronomical Society of the Pacific Conference Series, Vol. 411, p. 251.

Müller, K., Sinisalo, A., Anschütz, H., Hamran, S.-E., Hagen, J.-O., McConnell, J. R. and Pasteris, D. R., 2010. An 860 $\mathrm{km}$ surface mass-balance profile on the East Antarctic plateau derived by GPR. Annals of Glaciology 51, pp. 1-8.

Oza, S. R., Singh, R. K. K., Vyas, N. K. and Sarkar, A., 2011 Study of inter-annual variations in surface melting over Amery Ice Shelf, East Antarctica, using space-borne scatterometer data. Journal of Earth System Science 120, pp. 329-336.

Remy, F., Ledroit, M. and Minster, J. F., 1992. Katabatic wind intensity and direction over Antarctica derived from scatterometer data. Geophysical Research Letters 19, pp. 1021-1024.

Ulaby, F. T., Siquera, P., Nashashibi, A. and Sarabandi, K., 1996. Semi-empirical model for radar backscatter from snow at 35 and 95 GHz. IEEE Transactions on Geoscience and Remote Sensing 34, pp. 1059-1065.

Winebrenner, D. P., Arthern, R. J. and Shuman, C. A., 2001. Mapping Greenland accumulation rates using observations of thermal emission at $4.5-\mathrm{cm}$ wavelength. Journal of Geophysical Research 106, pp. 33919-33934.
Young, N. W. and Hyland, G., 1997. Applications of time series of microwave backscatter over the Antarctic region. In: Proceedings of the 3rd ERS Scientific Symposium, Florence, Italy.

Young, N. W., Hall, D. and Hyland, G., 1996. Directional anisotropy of C-band backscatter and microrelief in East Antarctica. In: Proceedings of the First Australian ERS Symposium, pp. 117-126. 